\title{
Bioelectrical Impedance Vector Analysis: A Valuable Tool to Monitor Daily Body Hydration Dynamics at Altitude
}

\author{
Ivo B. Regli ${ }^{1,2, *}$, Rachel Turner ${ }^{1}$, Simon Woyke ${ }^{1,3}$, Simon Rauch ${ }^{1,2} \mathbb{C}^{\text {, Hermann Brugger }}{ }^{1,3}$ (D) \\ and Hannes Gatterer ${ }^{1}$ (D) \\ 1 Institute of Mountain Emergency Medicine, Eurac Research, 39100 Bolzano, Italy; \\ Rachel.Turner@eurac.edu (R.T.); Simon.Woyke@i-med.ac.at (S.W.); Simon.Rauch@eurac.edu (S.R.); \\ Hermann.Brugger@eurac.edu (H.B.); Hannes.Gatterer@eurac.edu (H.G.) \\ 2 Department of Anaesthesia and Intensive Care, “F. Tappeiner" Hospital, 39012 Merano, Italy \\ 3 Department of Anaesthesiology and Intensive Care, Medical University, 6020 Innsbruck, Austria \\ * Correspondence: Ivo.Regli@eurac.edu
}

Citation: Regli, I.B.; Turner, R.; Woyke, S.; Rauch, S.; Brugger, H.; Gatterer, H. Bioelectrical Impedance Vector Analysis: A Valuable Tool to Monitor Daily Body Hydration Dynamics at Altitude. Int. J. Environ. Res. Public Health 2021, 18, 5455. https://doi.org/10.3390/ ijerph18105455

Academic Editors: Fernando Alacid, Lorena Correas Gómez and José Ramón Alvero Cruz

Received: 29 April 2021

Accepted: 16 May 2021

Published: 20 May 2021

Publisher's Note: MDPI stays neutral with regard to jurisdictional claims in published maps and institutional affiliations.

Copyright: (c) 2021 by the authors. Licensee MDPI, Basel, Switzerland. This article is an open access article distributed under the terms and conditions of the Creative Commons Attribution (CC BY) license (https:// creativecommons.org/licenses/by/ $4.0 /)$

\begin{abstract}
Bioelectrical impedance vector analysis (BIVA) is a method used to estimate variation in body hydration. We assessed the potential of BIVA for monitoring daily body hydration fluctuations in nine healthy, normally active males under matching normoxic (NX) and hypobaric hypoxic $(\mathrm{HH})$ experimental conditions. Furthermore, we aimed to investigate whether changes in BIVA may correspond with the development of acute mountain sickness (AMS). Subjects were exposed in a hypobaric chamber to both NX (corresponding to an altitude of $262 \mathrm{~m}$ ) and HH conditions corresponding to an altitude of $3500 \mathrm{~m}$ during two four-day sojourns within which food, water intake and physical activity were controlled. Bioimpedance and body weight measurements were performed three times a day and medical symptoms were assessed every morning using the Lake Louise score (LLS). Total body water (TBW) was also assessed on the last day of both sojourns using the deuterium dilution technique. We detected circadian changes in vector length, indicating circadian body water variations that did not differ between $\mathrm{NX}$ and $\mathrm{HH}$ conditions (ANOVA effects: time: $p=0.018$, eta ${ }^{2}=0.149$; interaction: $p=0.214$, eta ${ }^{2}=0.083$; condition: $p=0.920$, eta $^{2}=0.001$ ). Even though none of the subjects developed AMS, four subjects showed clinical symptoms according to the LLS during the first 24 hours of HH conditions. These subjects showed a pronounced (Cohen's d: 1.09$)$, yet not statistically significant $(p=0.206)$ decrease in phase angle 6 hours after exposure, which may indicate fluid shift from the intracellular to the extracellular compartment. At the end of each sojourn, vector length correlated with deuterium dilution TBW "gold standard" measurements (linear regression: NX: $p=0.002$ and $\mathrm{r}^{2}=0.756, \mathrm{HH}: p<0.001$ and $\mathrm{r}^{2}=0.84$ ). BIVA can be considered a valuable method for monitoring body hydration changes at altitude. Whether such changes are related to the development of clinical symptoms associated with AMS, as indicated in the present investigation, must be confirmed in future studies.
\end{abstract}

Keywords: bioimpedance; total body water; high altitude; acute mountain sickness; circadian rhythm; intracellular; extracellular

\section{Introduction}

Bioelectrical impendence analysis (BIA) is a non-invasive tool for assessing body hydration [1,2]. During bioelectrical impedance measurements, an alternating electrical current is delivered and electrical impedance $(Z)$, composed of electrical resistance $(R)$ and reactance $\left(X_{c}\right)$, is quantified. $R$ is determined by the body's resistive (i.e., opposition to flow of current) elements, and $X_{c}$ is determined by the body's capacitive elements; both differ between body fluids and structures [3,4]. Bioelectrical impendence vector analysis (BIVA) analyzes $\mathrm{R}$ and $\mathrm{X}_{\mathrm{c}}$ data using a vector-based approach, where changes in the vector lengths correspond to total body water variations, and changes in the phase angle (PA) resemble differences in the ratio of extracellular vs. intracellular water [2,5-10]. Thus far, BIVA has 
been used for monitoring body hydration in nephrology [11,12], nutritional sciences [13] in various clinical settings [3,14-16], sports science and medicine [7,10,17-27], pediatrics [28] and high-altitude medicine $[29,30]$.

Altitude exposure is known to acutely trigger several physiological processes, which may affect body fluid status [16], e.g., prompt increases in resting ventilation and heart rate [31], as well as direct or indirect adjustment of hormones involved in fluid regulation [32]. Interestingly, circadian oscillations of various vital parameters such as body temperature, breathing rate and blood pressure have been shown to be affected by hypoxia [33]. At sea level, body water variation determined by BIVA follows a circadian rhythm [34,35], but possible variations after acute exposure have previously not been investigated. Thus, the question arises whether prolonged, moderate altitude exposure also notably effects the circadian fluid rhythm. This may be of clinical importance when comparing hydration status under $\mathrm{HH}$ conditions to corresponding sea level values throughout the day. Moreover, changes in body hydration have been previously reported to be a risk factor in the development of acute mountain sickness (AMS) [9,36-44], even though contrasting data exist [45]. Accordingly, we aimed to assess whether circadian oscillation in TBW dynamics, as determined by BIVA, are influenced by prolonged exposure to $\mathrm{HH}$ conditions corresponding to $3500 \mathrm{~m}$. In addition, we intended to investigate whether it would be possible to connect measurable changes in TBW during a 4-day HH sojourn to AMS diagnoses or any singular AMS-related symptoms.

\section{Materials and Methods}

\subsection{Study Design}

The reported experiments were conducted during a project investigating plasma volume (PV) regulation in $\mathrm{HH}$. Detailed description of the overarching experimental approach is provided by Schlittler et al. [32].

Briefly, eleven healthy, young, male lowlanders were recruited as subjects ( $25 \pm 4$ years, $181 \pm 8 \mathrm{~cm}, 72 \pm 12 \mathrm{~kg}$, body mass index: $22 \pm 3 \mathrm{~kg} / \mathrm{m}^{2}$ ). Subjects completed two 4-day sojourns in a hypobaric chamber (terraXcube, Bolzano, Italy), one in $\mathrm{HH}$ corresponding to an altitude of $3500 \mathrm{~m}$ and one in NX (262 m).

The order of the sojourns was randomly assigned to each participant within a crossover design, and a four week 'wash-out' period was applied between sojourns. Four days prior and during each sojourn, participants adhered to standardized physical activity, food and fluid intake. Daily fluid intake was $3 \mathrm{~L}$ of water plus a cup of coffee, daily caloric intake was $2380 \mathrm{kcal}$ ( $51 \%$ carbohydrate, $13 \%$ protein, $36 \%$ fat), sodium intake was $100 \mathrm{mmol} /$ day, and potassium intake was $97 \mathrm{mmol} /$ day. Both the timing and content of meals were pre-determined and standardized between conditions. Main meals were served at 07:00, 13:00 and 19:00 each day within the hypobaric chamber. Habitual physical activity was measured with a step counter during the four days preceding the sojourn and step numbers were replicated during the sojourns, if necessary, using a treadmill. During the sojourns, the Lake Louise score (LLS) of each participant was determined every morning [46]. For the data presented in this article, two of the study subjects were excluded due to insufficient compliance with the BIVA protocol during the sojourns.

\subsection{BIVA Measurements}

Bioimpedance measurements were performed using an impedance plethysmograph (BIA 101 BIVA, AKERN SRL, Montacchielo, Italy) with a $250 \mu \mathrm{A}$ RMS $50 \mathrm{kHz}$ sinusoidal output signal. The device was calibrated using the standard control circuit supplied by the manufacturer with a known impedance (resistance $(R)=383 \mathrm{ohm}$; reactance $\left.\left(X_{c}\right)=45 \mathrm{ohm}\right)$. The accuracy of the device was $1 \%$ for $\mathrm{R}$ and $1 \%$ for Xc. Precision of BIA measurements, if performed under standardized conditions, is reported to be very good, with a variability of $1-2 \%$ [47,48]. In the present investigation, all measurements have been performed according to the manufacturer's guidelines, directly prior to breakfast, lunch and dinner. The subjects were in a supine position with their legs and arms by their sides and values 
were registered after a minimum of 5 min rest. Subjects were required to empty their bladder immediately before assuming the supine position. Prior to the measurement, the skin was cleaned with an alcohol solution and four contact electrodes (BIATRODES, AKERN SRL, Montacchielo, Italy) were placed on the dorsal surface of the right hand and foot according to the manufacturer's guidelines. Electrode positions were marked with a permanent marker to ensure consistent placement. Electrodes stayed in place during the day, were removed in the evening and, if necessary, were exchanged if the contact was not adequate [9].

Whole body resistance and reactance were assessed for each time point of interest. Data were analyzed applying the previously described BIVA method [2,11,29]. Measurements of resistance $(\mathrm{R})$ and reactance $\left(\mathrm{X}_{\mathrm{C}}\right)$ were standardized by the height of subjects and expressed in $\mathrm{ohm} / \mathrm{m}$ (i.e., $\mathrm{R} / \mathrm{H}$ and $\mathrm{Xc} / \mathrm{H}$ ). The combination of $\mathrm{R}$ (i.e., opposition to the flow of an alternating current through intra- and extracellular ionic solution) and $\mathrm{X}_{\mathrm{C}}$ (i.e., capacitive component of tissue interfaces, cell membranes and organelles) yields an impedance vector and a corresponding phase angle (geometric relationship $=$ arc tangent of $X_{c} / R$ expressed in degrees). The length of the vector, calculated as the hypotenuse of individual impedance values, is inversely related to TBW $[3,5,17]$. The PA is related to the intracellular water pool and the ratio of extracellular to intracellular volumes [6].

\subsection{Body Weight Measurements}

Body weight was measured directly before all bioimpedance measurements and after voiding. Participants were instructed to always wear the same clothing when weighing themselves.

\subsection{Deuterium-Based Total Body Water Measurements}

TBW data measured by deuterium dilution have been previously reported by Schlittler et al. [32]. We used these data, relating to the level of enrichment of deuterium in saliva, to compare BIVA and the deuterium dilution-derived TBW. Briefly, on the evening of the 4th day, before going to bed, the basal saliva sample was collected from each participant. Then, each participant ingested a precisely determined amount of deuterium which was pre-prepared from a stock solution. Ten hours after deuterium ingestion, during which participants abstained from eating or drinking, another saliva sample was collected. Deuterium enrichment of the second saliva sample, relative to the baseline sample, was assessed with isotope ratio mass spectrometry measurements. TBW was derived by calculating the deuterium dilution space while correcting for non-aqueous exchange using the method of Schoeller et al. [49].

\subsection{Statistical Analysis}

Based on the results of a study investigating vector length changes over the course of an 8-day altitude stay $(3,830 \mathrm{~m})$ [30], a sample size of $n=9$ resulted in a power $>80 \%$ to detect significant vector length changes (two-tailed, assumed $\mathrm{r}=0.6$ ). For the calculation, reported changes after $72 \mathrm{~h}$ were considered. ANOVA with a repeated measurement design was done using IBM SPSS 26.0 (Armonk, NY, USA). $p<0.05$ was considered statistically significant. Missing values ( $n=6$, pertaining to different subjects) were replaced with the mean of the respected daytime measurements of the remaining days. Data are shown as mean \pm SEM and if there was an adequate effect size (ES, partial eta ${ }^{2}$ or Cohen's d as indicated in the text). For better legibility, SEM is not shown for body weight data. Linear regression analysis and unpaired t-tests with Welch's correction comparison were completed with GraphPad Prism 6 (San Diego, CA, USA).

\section{Results}

\subsection{Circadian Body Fluid Fluctuations at NX and HH}

During both the NX and HH sojourn, we detected similar circadian rhythms with the longest vectors measured in the morning and shorter ones during the day and in the 
evening (Figure 1A, ANOVA effects: time: $p=0.018$, eta ${ }^{2}=0.149$; interaction: $p=0.214$, eta $^{2}=0.083$; condition: $p=0.920$, eta ${ }^{2}=0.001$ ). Except for the first day, the longest vectors were found in the morning and shorter ones at noon and in the evening. During both stays, vector lengths were within the $75 \%$ tolerance ellipse of the general healthy Italian male population [50]. Figure 1B,C demonstrate this for days 1 and 4 in the NX and the $\mathrm{HH}$ sojourn. Additionally, between conditions ( $\mathrm{NX}$ and $\mathrm{HH}$ ) no differences in vector length were identified (ANOVA effect condition: $p=0.920$, eta $^{2}=0.001$ ).

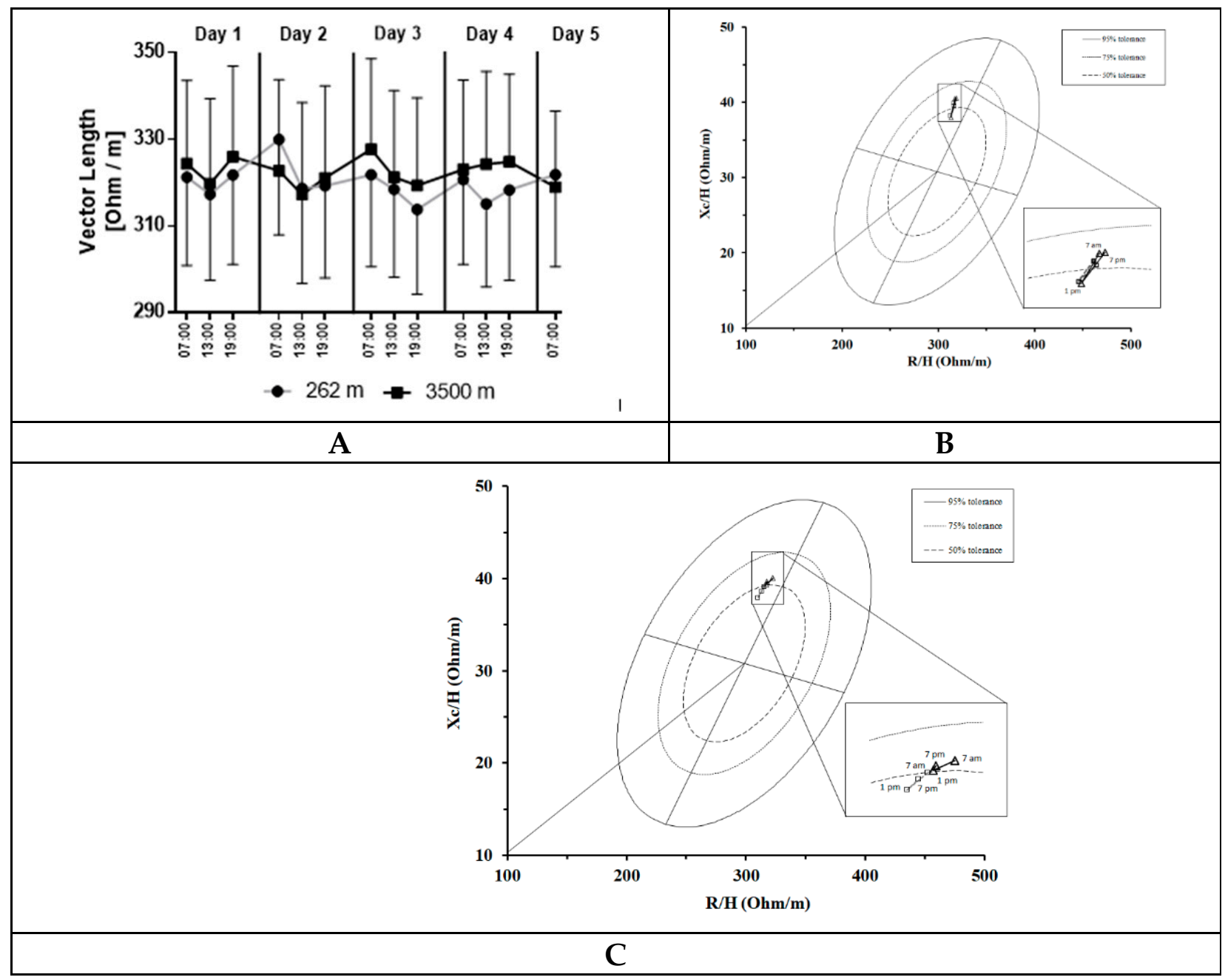

Figure 1. BIVA vector length over time. (A) Data represented as mean and standard error of mean (error bars) of nine subjects. ANOVA effects: time: $p=0.018$, eta ${ }^{2}=0.149$; interaction: $p=0.214$, eta ${ }^{2}=0.083$; condition: $p=0.920$, eta ${ }^{2}=0.001$. (B) Mean vector shifts during day 1, triangles: altitude, squares: sea level, plotted on the 50\%, 75\% and 95\% tolerance ellipse of the general healthy Italian male population. (C) Mean vector shifts during day 4, triangles: altitude, squares: sea level, plotted on the $50 \%, 75 \%$ and $95 \%$ tolerance ellipse of the general healthy Italian male population.

Each participant's body weight showed a similar dynamic and no differences between conditions (Figure 2, ANOVA effects: time: $<0.001$, eta ${ }^{2}=0.265$; interaction: $p=0.403$, eta $^{2}=0.061$; condition: $p=0.999$, eta ${ }^{2}=<0.001$ ). Similar body weight changes were found in both sojourns, with the lowest weights recorded in the morning and higher values at noon and in the evening. Body weight measurements of the first morning were excluded due to missing data (due to the unfamiliar situation, some subjects forgot to fill in the pre-prepared log on the first morning). 


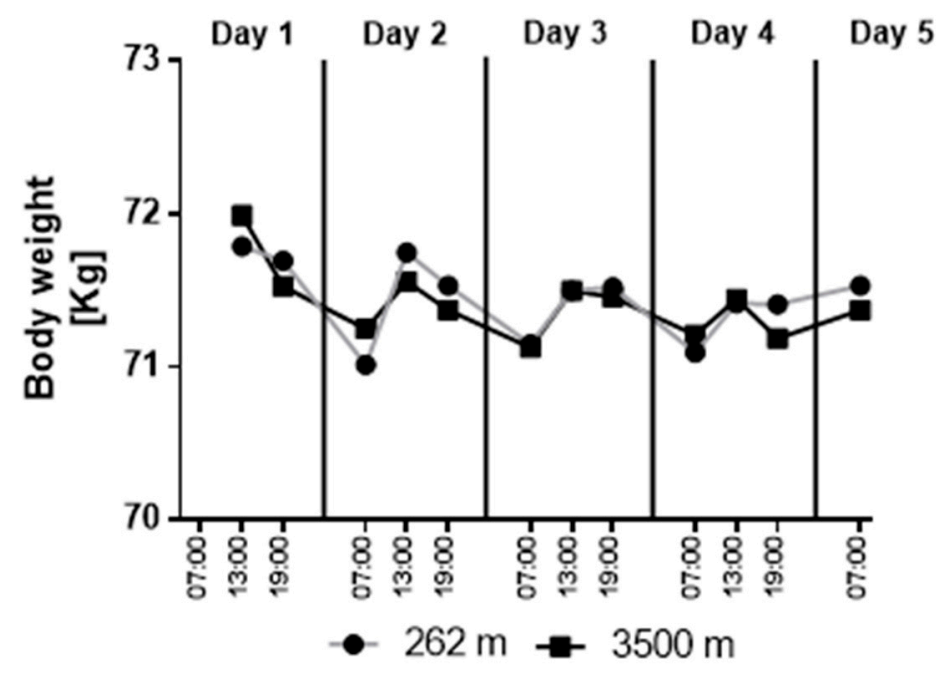

Figure 2. Body weight over time. Data represented as the mean of nine subjects. ANOVA effects: time: $<0.001$, eta ${ }^{2}=0.265$; interaction: $p=0.403$, eta ${ }^{2}=0.061$; condition: $p=0.999$, eta $^{2}=<0.001$.

\subsection{AMS-Related Clinical Symptoms and BIVA Parameters}

None of the subjects developed AMS. After 24 hours at $3500 \mathrm{~m}$, four out of nine subjects reported single symptoms according to the LLS $(0<\mathrm{LLS}<3)$. One participant experienced mild fatigue and weakness and three participants complained about mild headache. During the normobaric sojourn, none of the participants showed any clinical symptoms.

The presence of symptoms according to the LLS was accompanied by a more pronounced transient decrease in PA during the first hours (Figure 3). Even though statistical significance was not reached, the increase was most marked 6 hours after simulated ascent $(p=0.206$, ES (Cohen's d) $=1.09)$ but was no longer apparent after 24 hours.

$$
\text { Day } 1 \quad \text { Day } 2
$$

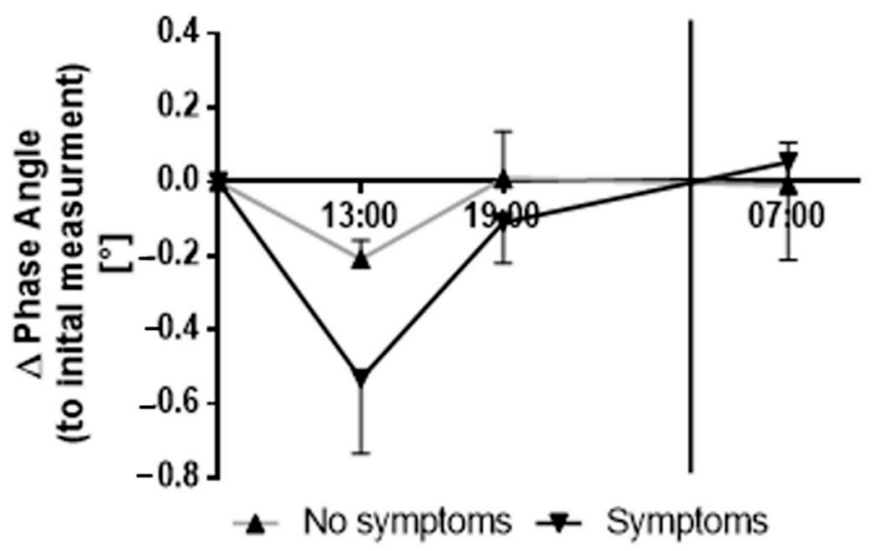

Figure 3. Change in phase angle (PA) from the initial value after simulated ascent. Data from 5 subjects without symptoms are represented with a gray line and upwards-pointing triangles $(\mathbf{\Delta})$. Data from 4 subjects with symptoms are represented with a black line and downwards-pointing triangles $(\boldsymbol{\nabla})$. Data represented as mean and standard error of mean (error bars). Unpaired t-test with Welch's correction used to analyze changes within the first 6 hours: $p=0.206$; ES Cohen's: $d=1.09$.

\subsection{Vector Length and Deuterium Dilution Total Body Water}

Similar to vector length, TBW did not differ between conditions ( $p=0.171$ [32]). To test whether BIVA-derived vector lengths are suitable as surrogate markers of TBW status, we correlated the deuterium-based TBW measurements of each participant with their concurrent BIVA measurements. We found a high degree of correlation between these two 
values in both the NX setting $\left(\mathrm{r}^{2}=0.756 p=0.002\right)$ and the HH setting $\left(\mathrm{r}^{2}=0.845, p<0.001\right)$ (Figure 4).

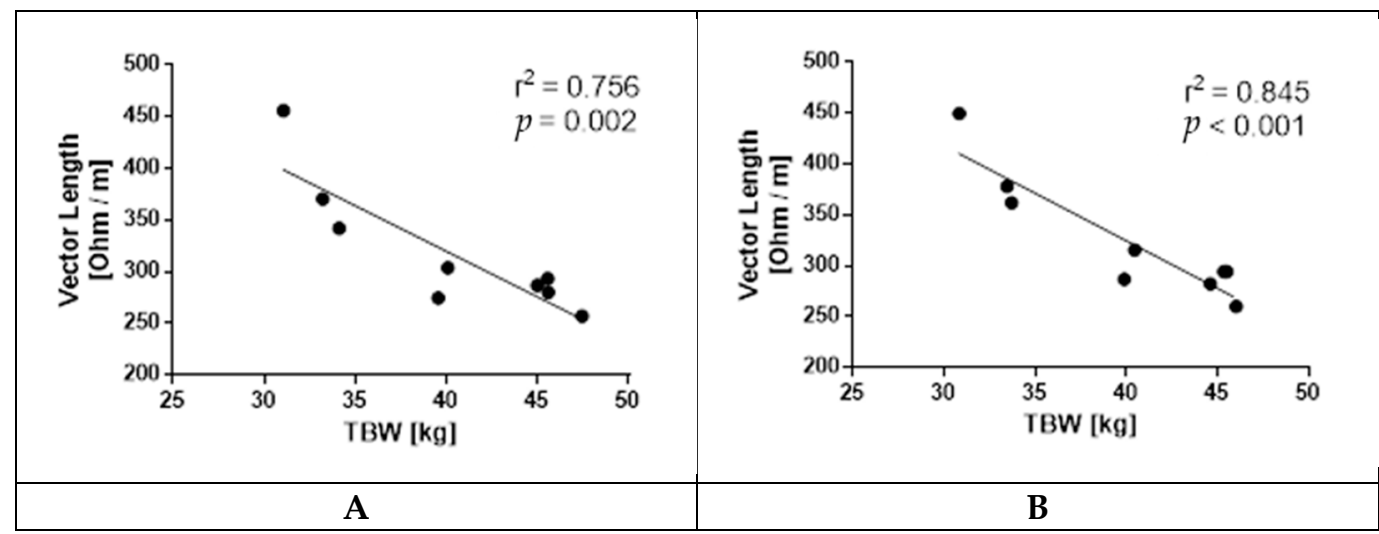

Figure 4. Correlation between total body water (TBW) and vector length. (A) Individual data points for deuterium dilution TBW measurements and BIVA measurements taken at the same time at NX. Linear regression: $p=0.002$ and $\mathrm{r}^{2}=0.756$. (B) Individual data points for deuterium dilution TBW measurements and BIVA measurements taken at the same time at HH. Linear regression: $p<0.001$ and $\mathrm{r}^{2}=0.845$.

\section{Discussion}

Our main finding is that when physical activity, diet and fluid intake are controlled for, TBW circadian rhythm is not influenced by a prolonged hypobaric hypoxic exposure corresponding to $3500 \mathrm{~m}$. Previous studies have revealed that, at sea level, total body water content is subject to circadian fluctuations in healthy volunteers [34,35]. Others report a continuous increase in bioimpedance upon supine positioning of volunteers for 12 hours [51,52]. However, the exact dynamics of this circadian rhythm have not been previously investigated under such controlled conditions, and therefore remain a source of debate.

For most days, our data repeatedly show the longest vector (indicating less fluid) in the early morning and shorter ones (indicating fluid gain) later at 13:00 in the afternoon and 19:00 in the evening, findings that are similar to those of Buemi et al. [34]. However, no exact pattern can be discerned regarding whether vector length is different at noon or in the evening, probably due to our study subjects undergoing normal physical activity throughout the day instead of being kept in a supine position for prolonged periods of time [34].

Hypoxia influences a variety of hormones involved in fluid regulation [32] and thus it seemed reasonable to hypothesize that TBW circadian rhythm may also be altered. In contrast to our hypothesis, data showed that the circadian rhythm of fluid balance was not affected by exposure to a simulated altitude of $3500 \mathrm{~m}$. Since no fluid volume changes occurred during a prolonged sojourn at this altitude equivalent [32], we may conclude that the level of hypoxia might have been too low to exert significant alterations in TBW and consequently have had little or no effect on fluid circadian rhythm. Whereas, at higher altitudes, body fluid disturbance may be more probable due to potentially higher hormonally induced diuresis and natriuresis, decreased voluntary salt and water intake and increased insensible water loss (respiratory and surface water loss) [53]. Accordingly, Piccoli et al. showed that a significant BIVA vector lengthening compared to sea level can be detected at 5050m [29]. Furthermore, they showed that changes in BIVA vector lengths correlated significantly with changes in body weight, which is in line with our findings. However, it must be considered that the physical activity as well as the degree and duration of hypoxia differed considerably from our study. Furthermore, they showed that plasma osmolality, and serum $\mathrm{Na}+, \mathrm{K}+, \mathrm{Cl}$ - and glucose significantly correlated with BIVA vector length. Moreover, Strapazzon et al. showed that there are significant changes in BIVA vector length upon effortless exposure to an altitude of $3830 \mathrm{~m}$ for up to 72 hours [30]. 
However, here there was no correlation between plasma and serum parameters and BIVA vector length. Although this study was more similar to our study with regard to physical activity as well as the degree and duration of hypoxia, it must still be considered that in the infield setting it is much more difficult to control all the potential confounding parameters. Gatterer et al. showed that there is significant shortening of BIVA vector lengths upon exposure of participants to a $\mathrm{FiO}_{2}$ of 0.126 (corresponding to hypoxia at $4500 \mathrm{~m}$ ) for $12 \mathrm{~h}$ [9]. Moreover, there was a significant decrease in serum $\mathrm{Na}+$ and plasma osmolality. Even though, here, the data stem from a controlled environment, it must be considered that the setting of this study is considerably different to ours regarding the degree and duration of hypoxia, the absence of hypobaria and the lack of physical activity. Finally, in women exposed to an altitude of $5050 \mathrm{~m}$ for 21 days after a 5 day hike from $2866 \mathrm{~m}$, an absence of changes in vector length has been shown [54]. Here also, differences in the degree of hypoxia, the duration of exposure to hypoxia and the amount of physical activity must be considered. Most importantly, our study is the first to include an NX control sojourn, which allows us to better exclude any confounding factors. Nonetheless, despite our current findings, it could be speculated that above a $3500 \mathrm{~m}$ equivalent, fluid circadian rhythm may also be affected by $\mathrm{HH}$, which should be further addressed in future studies. Interestingly, fluctuations in body weight over the course of the HH sojourn were in agreement with changes in vector length. Thus, our data indicate that under strictly controlled and standardized conditions, body weight changes may reflect subtle TBW changes throughout the course of the day, similarly to BIVA. This warrants further consideration in future investigations involving the assessment of TBW, where normally a lack of control dictates that only initial morning body weight measures are considered adequate for fluid status monitoring [55].

In contrast to our expectations, none of the participants developed AMS during the altitude stay [56]. Therefore, it was not possible to link changes in BIVA values to the development of AMS. Nonetheless, participants identified as having singular symptoms according to the LLS after the first 24 hours of $\mathrm{HH}$ exposure showed a large, yet not significant, decrease in PA in the hours prior (6 hours; ES = 1.09), which could indicate an initial fluid shift to the extracellular compartment $[5,6]$. Indeed, body fluid alterations upon ascent to altitude have been previously related to the development of high-altitude illnesses [9,36-42,57]. Notably, early fluid retention as a result of fluid shifts between intracellular and extracellular water compartments seem to be especially associated with higher AMS occurrence $[9,42]$. However, in our study, no additional change in vector length was detected in participants showing these symptoms compared to those who remained asymptomatic throughout the exposure. Equally, the initial decrease in PA within the first $6 \mathrm{~h}$ was not apparent after $12 \mathrm{~h}$ of $\mathrm{HH}$ exposure and overall TBW remained unchanged after 4 days of continuous $\mathrm{HH}$ exposure. Interestingly, this observation is consistent with previous reports showing that AMS is not associated with changes in TBW [45].

We showed that vector length correlated well with deuterium dilution TBW measurements, widely considered the "gold standard", confirming that vector length provides specific information on total body water content [3]. The lack of differences in vector length dynamics between the NX and $\mathrm{HH}$ sojourn corresponds to the data of the deuterium dilution-based TBW measurements of Schlittler et al. [32].

\section{Limitations}

Some limitations have to be acknowledged. As mentioned, contrary to our expectations, none of the participant suffered from AMS and therefore it was not possible to establish whether early body fluid changes correspond with AMS development in our setting. Nonetheless, we were able to note differences between those participants who developed single symptoms and participants who remained completely asymptomatic. These changes did not reach statistical significance even though effect size was large $(E S=1.09)$. In this regard, the small sample size and thus the limited statistical power must 
be recognized as another limitation; therefore confirmation of the present results by further investigation is necessary to draw firm conclusions on this issue.

\section{Conclusions}

In comparison with an NX control, prolonged exposure to a 3500 m equivalent does not alter overall fluid circadian rhythm. In the future, BIVA may present as a practical tool to monitor changes in TBW status under hypobaric hypoxic conditions, if adequate methodological controls are employed relating to diet and fluid intake. Whether changes in TBW are clearly related to the development of clinical symptoms associated with AMS, and are adequately characterized by vector length and PA, remains to be confirmed in future studies.

Author Contributions: Conceptualization, I.B.R. and H.G.; methodology, I.B.R. and H.G.; software, I.B.R. and H.G.; validation, I.B.R., R.T., S.W., S.R., H.B. and H.G.; formal analysis, I.B.R. and H.G.; investigation, I.B.R., R.T., S.W., S.R. and H.G.; resources, H.B. and H.G.; data curation, I.B.R. and H.G.; writing—original draft preparation, I.B.R. and H.G.; writing—review and editing, I.B.R., R.T., S.W., S.R., H.B. and H.G.; visualization, I.B.R.; supervision, H.B. and H.G.; project administration, H.G.; funding acquisition, H.G. All authors have read and agreed to the published version of the manuscript.

Funding: This research was funded by the Swiss National Centre of Competence in Research (NCCR), Kidney Control of Homeostasis (Kidney.CH).

Institutional Review Board Statement: The study was conducted according to the guidelines of the Declaration of Helsinki and approved by the Ethics Committee of the South Tyrolian Health Care System (No 70-2019 and date of approval 2 October 2019).

Informed Consent Statement: Informed consent was obtained from all subjects involved in the study.

Data Availability Statement: The datasets generated and/or analyzed during the current study are available from the corresponding author on reasonable request.

Acknowledgments: We thank the Department of Innovation, Research and University of the Autonomous Province of Bozen/Bolzano for covering the open access publication costs. Moreover, we thank the staff of terraXcube and Berenice Martinez Salazar for their outstanding support.

Conflicts of Interest: The authors declare no conflict of interest.

\section{References}

1. Lukaski, H.C.; Moore, M. Bioelectrical Impedance Assessment of Wound Healing. J. Diabetes Sci. Technol. 2012, 6, 209-212. [CrossRef] [PubMed]

2. Piccoli, A.; Rossi, B.; Pillon, L.; Bucciante, G. A new method for monitoring body fluid variation by bioimpedance analysis: The RXc graph. Kidney Int. 1994, 46, 534-539. [CrossRef] [PubMed]

3. Lukaski, H.C.; Diaz, N.V.; Talluri, A.; Nescolarde, L. Classification of Hydration in Clinical Conditions: Indirect and Direct Approaches Using Bioimpedance. Nutrients 2019, 11, 809. [CrossRef]

4. Barbosa-Silva, M.C.G.; Barros, A.J.D. Bioelectrical impedance analysis in clinical practice: A new perspective on its use beyond body composition equations. Curr. Opin. Clin. Nutr. Metab. Care 2005, 8, 311-317. [CrossRef]

5. Marini, E.; Campa, F.; Buffa, R.; Stagi, S.; Matias, C.N.; Toselli, S.; Sardinha, L.; Silva, A.M. Phase angle and bioelectrical impedance vector analysis in the evaluation of body composition in athletes. Clin. Nutr. 2020, 39, 447-454. [CrossRef]

6. Francisco, R.; Matias, C.N.; Santos, D.A.; Campa, F.; Minderico, C.S.; Rocha, P.; Heymsfield, S.B.; Lukaski, H.; Sardinha, L.B.; Silva, A.M. The Predictive Role of Raw Bioelectrical Impedance Parameters in Water Compartments and Fluid Distribution Assessed by Dilution Techniques in Athletes. Int. J. Environ. Res. Public Health 2020, 17, 759. [CrossRef]

7. Campa, F.; Gatterer, H.; Lukaski, H.; Toselli, S. Stabilizing Bioimpedance-Vector-Analysis Measures With a 10-Minute Cold Shower After Running Exercise to Enable Assessment of Body Hydration. Int. J. Sports Physiol. Perform. 2019, 14, 1006-1009. [CrossRef]

8. Gatterer, H.; Schenk, K.; Laninschegg, L.; Schlemmer, P.; Lukaski, H.; Burtscher, M. Bioimpedance Identifies Body Fluid Loss after Exercise in the Heat: A Pilot Study with Body Cooling. PLoS ONE 2014, 9, e109729. [CrossRef] [PubMed]

9. Gatterer, H.; Wille, M.; Faulhaber, M.; Lukaski, H.; Melmer, A.; Ebenbichler, C.; Burtscher, M. Association between Body Water Status and Acute Mountain Sickness. PLoS ONE 2013, 8, e73185. [CrossRef] 
10. Campa, F.; Matias, C.N.; Marini, E.; Heymsfield, S.B.; Toselli, S.; Sardinha, L.; Silva, A.M. Identifying Athlete Body Fluid Changes During a Competitive Season with Bioelectrical Impedance Vector Analysis. Int. J. Sports Physiol. Perform. 2019, 15, 361-367. [CrossRef]

11. Piccoli, A. Bioelectric Impedance Measurement for Fluid Status Assessment. Contrib. Nephrol. 2010, 164, 143-152. [CrossRef]

12. Battaglia, Y.; Ullo, I.; Massarenti, S.; Esposito, P.; Prencipe, M.; Ciancio, G.; Provenzano, M.; Fiorini, F.; Andreucci, M.; Storari, A.; et al. Ultrasonography of Quadriceps Femoris Muscle and Subcutaneous Fat Tissue and Body Composition by BIVA in Chronic Dialysis Patients. Nutrients 2020, 12, 1388. [CrossRef] [PubMed]

13. Buffa, R.; Saragat, B.; Cabras, S.; Rinaldi, A.C.; Marini, E. Accuracy of Specific BIVA for the Assessment of Body Composition in the United States Population. PLoS ONE 2013, 8, e58533. [CrossRef] [PubMed]

14. Razzera, E.L.; Marcadenti, A.; Rovedder, S.W.; Alves, F.D.; Fink, J.D.S.; Silva, F.M. Parameters of Bioelectrical Impedance Are Good Predictors of Nutrition Risk, Length of Stay, and Mortality in Critically Ill Patients: A Prospective Cohort Study. J. Parenter. Enter. Nutr. 2020, 44, 849-854. [CrossRef]

15. Del Giorno, R.; Quarenghi, M.; Stefanelli, K.; Rigamonti, A.; Stanglini, C.; De Vecchi, V.; Gabutti, L. Phase angle is associated with length of hospital stay, readmissions, mortality, and falls in patients hospitalized in internal-medicine wards: A retrospective cohort study. Nutrition 2021, 85, 111068. [CrossRef]

16. Matias, C.N.; Cavaco-Silva, J.; Reis, M.; Campa, F.; Toselli, S.; Sardinha, L.; Silva, A.M. Phase Angle as a Marker of Muscular Strength in Breast Cancer Survivors. Int. J. Environ. Res. Public Health 2020, 17, 4452. [CrossRef]

17. Pollastri, L.; Lanfranconi, F.; Tredici, G.; Schenk, K.; Burtscher, M.; Gatterer, H. Body fluid status and physical demand during the Giro d'Italia. Res. Sports Med. 2016, 24, 30-38. [CrossRef]

18. Bongiovanni, T.; Mascherini, G.; Genovesi, F.; Pasta, G.; Iaia, F.M.; Trecroci, A.; Ventimiglia, M.; Alberti, G.; Campa, F. Bioimpedance Vector References Need to Be Period-Specific for Assessing Body Composition and Cellular Health in Elite Soccer Players: A Brief Report. J. Funct. Morphol. Kinesiol. 2020, 5, 73. [CrossRef]

19. Martins, P.; Teixeira, A.; Guglielmo, L.; Francisco, J.; Silva, D.; Nakamura, F.; Lima, L. Phase Angle Is Related to $10 \mathrm{~m}$ and $30 \mathrm{~m}$ Sprint Time and Repeated-Sprint Ability in Young Male Soccer Players. Int. J. Environ. Res. Public Health 2021, 18, 4405. [CrossRef]

20. Campa, F.; Silva, A.M.; Matias, C.N.; Monteiro, C.P.; Paoli, A.; Nunes, J.P.; Talluri, J.; Lukaski, H.; Toselli, S. Body Water Content and Morphological Characteristics Modify Bioimpedance Vector Patterns in Volleyball, Soccer, and Rugby Players. Int. J. Environ. Res. Public Health 2020, 17, 6604. [CrossRef] [PubMed]

21. Reis, J.F.; Matias, C.N.; Campa, F.; Morgado, J.P.; Franco, P.; Quaresma, P.; Almeida, N.; Curto, D.; Toselli, S.; Monteiro, C.P. Bioimpedance Vector Patterns Changes in Response to Swimming Training: An Ecological Approach. Int. J. Environ. Res. Public Health 2020, 17, 4851. [CrossRef] [PubMed]

22. Stagi, S.; Doneddu, A.; Mulliri, G.; Ghiani, G.; Succa, V.; Crisafulli, A.; Marini, E. Lower Percentage of Fat Mass among Tai Chi Chuan Practitioners. Int. J. Environ. Res. Public Health 2020, 17, 1232. [CrossRef] [PubMed]

23. Toselli, S.; Marini, E.; Latessa, P.M.; Benedetti, L.; Campa, F. Maturity Related Differences in Body Composition Assessed by Classic and Specific Bioimpedance Vector Analysis among Male Elite Youth Soccer Players. Int. J. Environ. Res. Public Health 2020, 17, 729. [CrossRef] [PubMed]

24. Campa, F.; Matias, C.; Gatterer, H.; Toselli, S.; Koury, J.C.; Andreoli, A.; Melchiorri, G.; Sardinha, L.B.; Silva, A.M. Classic Bioelectrical Impedance Vector Reference Values for Assessing Body Composition in Male and Female Athletes. Int. J. Environ. Res. Public Health 2019, 16, 5066. [CrossRef] [PubMed]

25. Campa, F.; Silva, A.M.; Iannuzzi, V.; Mascherini, G.; Benedetti, L.; Toselli, S. The Role of Somatic Maturation on Bioimpedance Patterns and Body Composition in Male Elite Youth Soccer Players. Int. J. Environ. Res. Public Health 2019, 16, 4711. [CrossRef]

26. Toselli, S.; Badicu, G.; Bragonzoni, L.; Spiga, F.; Mazzuca, P.; Campa, F. Comparison of the Effect of Different Resistance Training Frequencies on Phase Angle and Handgrip Strength in Obese Women: A Randomized Controlled Trial. Int. J. Environ. Res. Public Health 2020, 17, 1163. [CrossRef]

27. Campa, F.; Toselli, S.; Mazzilli, M.; Gobbo, L.; Coratella, G. Assessment of Body Composition in Athletes: A Narrative Review of Available Methods with Special Reference to Quantitative and Qualitative Bioimpedance Analysis. Nutrients 2021, 13, 1620. [CrossRef]

28. Vermeulen, K.M.; Lopes, M.M.G.D.; Alves, C.X.; Brito, N.J.N.; Almeida, M.D.G.; Leite-Lais, L.; Vale, S.H.L.; Brandão-Neto, J. Bioelectrical Impedance Vector Analysis and Phase Angle on Different Oral Zinc Supplementation in Eutrophic Children: Randomized Triple-Blind Study. Nutrients 2019, 11, 1215. [CrossRef]

29. Piccoli, A.; Piazza, P.; Noventa, D.; Pillon, L.; Zaccaria, M. A new method for monitoring hydration at high altitude by bioimpedance analysis. Med. Sci. Sports Exerc. 1996, 28, 1517-1522. [CrossRef]

30. Strapazzon, G.; Pun, M.; Cappello, T.D.; Procter, E.; Lochner, P.; Brugger, H.; Piccoli, A. Total Body Water Dynamics Estimated with Bioelectrical Impedance Vector Analysis and B-Type Natriuretic Peptide After Exposure to Hypobaric Hypoxia: A Field Study. High Alt. Med. Biol. 2017, 18, 384-391. [CrossRef]

31. West, J.B. The physiologic basis of high-altitude diseases. Ann. Intern. Med. 2004, 141, 789-800. [CrossRef] [PubMed]

32. Schlittler, M.; Gatterer, H.; Turner, R.; Regli, I.B.; Woyke, S.; Strapazzon, G.; Rasmussen, P.; Kob, M.; Mueller, T.; Goetze, J.P.; et al. Regulation of plasma volume in male lowlanders during four days of exposure to hypobaric hypoxia equivalent to 3,500 $\mathrm{m}$ altitude. J. Physiol. 2021, 599, 1083-1096. [CrossRef] [PubMed] 
33. Bosco, G.; Ionadi, A.; Panico, S.; Faralli, F.; Gagliardi, R.; Data, P.; Mortola, J.P. Effects of Hypoxia on the Circadian Patterns in Men. High Alt. Med. Biol. 2003, 4, 305-318. [CrossRef] [PubMed]

34. Buemi, M.; Campo, S.; Sturiale, A.; Aloisi, C.; Romeo, A.; Nostro, L.; Crascì, E.; Ruello, A.; Manfredini, R.; Floccari, F.; et al. Circadian Rhythm of Hydration in Healthy Subjects and Uremic Patients Studied by Bioelectrical Impedance Analysis. Nephron Physiol. 2007, 106, p39-p44. [CrossRef]

35. Cugini, P.; Salandri, A.; Petrangeli, C.M.; Capodaglio, P.F.; Giovannini, C. Circadian Rhythms in Human Body Composition. Chrono- Int. 1996, 13, 359-371. [CrossRef]

36. Castellani, J.W.; Muza, S.R.; Cheuvront, S.N.; Sils, I.V.; Fulco, C.S.; Kenefick, R.W.; Beidleman, B.A.; Sawka, M.N. Effect of hypohydration and altitude exposure on aerobic exercise performance and acute mountain sickness. J. Appl. Physiol. 2010, 109, 1792-1800. [CrossRef]

37. Basnyat, B.; LeMaster, J.; Litch, J.A. Everest or bust: A cross sectional, epidemiological study of acute mountain sickness at 4243 meters in the Himalayas. Aviat. Space. Environ. Med. 1999, 70, 867-873.

38. Nerín, M.A.; Palop, J.; Montaño, J.A.; Morandeira, J.R.; Vázquez, M. Acute Mountain Sickness: Influence of Fluid Intake. Wilderness Environ. Med. 2006, 17, 215-220. [CrossRef]

39. Norris, J.N.; Viirre, E.; Aralis, H.; Sracic, M.K.; Thomas, D.; Gertsch, J.H. High Altitude Headache and Acute Mountain Sickness at Moderate Elevations in a Military Population During Battalion-Level Training Exercises. Mil. Med. 2012, 177, 917-923. [CrossRef]

40. Richardson, A.; Watt, P.; Maxwell, N. The effect of hypohydration severity on the physiological, psychological and renal hormonal responses to hypoxic exercise. Graefe's Arch. Clin. Exp. Ophthalmol. 2009, 106, 123-130. [CrossRef]

41. Loeppky, J.A.; Icenogle, M.V.; Maes, D.; Riboni, K.; Hinghofer-Szalkay, H.; Roach, R.C. Early fluid retention and severe acute mountain sickness. J. Appl. Physiol. 2005, 98, 591-597. [CrossRef] [PubMed]

42. Westerterp, K.R.; Robach, P.; Wouters, L.; Richalet, J.P. Water balance and acute mountain sickness before and after arrival at high altitude of 4,350 m. J. Appl. Physiol. 1996, 80, 1968-1972. [CrossRef] [PubMed]

43. Hackett, P.H.; Rennie, D. Rales, peripheral edema, retinal hemorrhage and acute mountain sickness. Am. J. Med. 1979, 67, 214-218. [CrossRef]

44. Hackett, P.H.; Rennie, D.; Grover, R.F.; Reeves, J.T. Acute mountain sickness and the edemas of high altitude: A common pathogenesis? Respir. Physiol. 1981, 46, 383-390. [CrossRef]

45. Biollaz, J.; Buclin, T.; Hildebrandt, W.; Décosterd, L.A.; Nussberger, J.; Swenson, E.R.; Bärtsch, P. No renal dysfunction or salt and water retention in acute mountain sickness at 4,559 $\mathrm{m}$ among young resting males after passive ascent. J. Appl. Physiol. 2021, 130, 226-236. [CrossRef] [PubMed]

46. Roach, R.C.; Hackett, P.H.; Oelz, O.; Bärtsch, P.; Luks, A.M.; MacInnis, M.J.; Baillie, J.K.; Achatz, E.; Albert, E.; Andrews, J.S.; et al. The 2018 Lake Louise Acute Mountain Sickness Score. High Alt. Med. Biol. 2018, 19, 4-6. [CrossRef] [PubMed]

47. Gatterer, H.; Schenk, K.; Burtscher, M.; Lukaski, H. Assessment of Human Body Composition Methods and Limitations. In Body Composition; CRC Press: Boca Raton, FL, USA, 2017; pp. 13-26.

48. Cornejo-Pareja, I.; Vegas-Aguilar, I.M.; García-Almeida, J.M.; Bellido-Guerrero, D.; Talluri, A.; Lukaski, H.; Tinahones, F.J. Phase angle and standardized phase angle from bioelectrical impedance measurements as a prognostic factor for mortality at 90 days in patients with COVID-19: A longitudinal cohort study. Clin. Nutr. 2021, in press. [CrossRef]

49. Schoeller, D.A.; Van Santen, E.; Peterson, D.W.; Dietz, W.; Jaspan, J.; Klein, P.D. Total body water measurement in humans with $18 \mathrm{O}$ and $2 \mathrm{H}$ labeled water. Am. J. Clin. Nutr. 1980, 33, 2686-2693. [CrossRef]

50. Piccoli, A.; Nigrelli, S.; Caberlotto, A.; Bottazzo, S.; Rossi, B.; Pillon, L.; Maggiore, Q. Bivariate normal values of the bioe-lectrical impedance vector in adult and elderly populations. Am. J. Clin. Nutr. 1995, 61, 269-270. [CrossRef]

51. Evans, W.; McClagish, H.; Trudgett, C. Factors affecting the In vivo precision of bioelectrical impedance analysis. Appl. Radiat. Isot. 1998, 49, 485-487. [CrossRef]

52. Slinde, F.; Bark, A.; Jansson, J.; Rossander-Hulthén, L. Bioelectrical impedance variation in healthy subjects during $12 \mathrm{~h}$ in the supine position. Clin. Nutr. 2003, 22, 153-157. [CrossRef] [PubMed]

53. Dünnwald, T.; Gatterer, H.; Faulhaber, M.; Arvandi, M.; Schobersberger, W. Body Composition and Body Weight Changes at Different Altitude Levels: A Systematic Review and Meta-Analysis. Front. Physiol. 2019, 10, 430. [CrossRef] [PubMed]

54. Ermolao, A.; Bergamin, M.; Rossi, A.C.; Carbonare, L.D.; Zaccaria, M. Cardiopulmonary Response and Body Composition Changes after Prolonged High Altitude Exposure in Women. High Alt. Med. Biol. 2011, 12, 357-369. [CrossRef]

55. Sawka, M.N.; Burke, L.M.; Eichner, E.R.; Maughan, R.J.; Montain, S.J.; Stachenfeld, N.S. American College of Sports Medicine position stand. Exercise and fluid replacement. Med. Sci. Sports Exerc. 2007, 39, 377-390. [CrossRef] [PubMed]

56. Berger, M.M.; Sareban, M.; Bärtsch, P. Acute mountain sickness: Do different time courses point to different pathophysiological mechanisms? J. Appl. Physiol. 2020, 128, 952-959. [CrossRef] [PubMed]

57. Richardson, A.; Watt, P.; Maxwell, N. Hydration and the Physiological Responses to Acute Normobaric Hypoxia. Wilderness Environ. Med. 2009, 20, 212-220. [CrossRef] [PubMed] 